\title{
QUALIDADE INDUSTRIAL E MATURAÇÃO DE FRUTOS DE LARANJEIRA 'VALÊNCIA' SOBRE SEIS PORTA-ENXERTOS ${ }^{1}$
}

\author{
PEDRO ANTONIO MARTINS AULER ${ }^{2}$, ANA CRISTINA GRADE FIORI-TUTIDA ${ }^{3}$, \\ MARIA BRÍGIDA DOS SANTOS SCHOLZ ${ }^{4}$
}

RESUMO - Com o objetivo de avaliar a influência de seis porta-enxertos sobre a maturação e as características físico-químicas de frutos de laranjeira 'Valência', instalou-se um experimento em janeiro de 1994, no município de Nova Esperança-PR. O delineamento experimental foi de blocos ao acaso, com quatro repetições, três plantas úteis por parcela e seis tratamentos, constituídos pelos porta-enxertos: limoeiro 'Cravo' (Citrus limonia), tangerineiras 'Cleópatra' (C. reshni) e 'Sunki' (C. sunki), citrangeiro 'Troyer' (Poncirus trifoliata x C. sinensis), tangeleiro 'Orlando' (C. tangerina x C. paradisi) e laranjeira 'Caipira' (C. sinensis). Avaliou-se a qualidade dos frutos em sete safras e a curva de maturação foi estimada para os anos de 1999 e 2000. Todos os porta-enxertos proporcionaram qualidade aceitável aos frutos da laranjeira 'Valência', com destaque para o citrangeiro 'Troyer' que superou o limoeiro 'Cravo' em rendimento industrial. Em um ano considerado com padrão climático normal, a evolução do índice tecnológico ajustou-se a uma equação de regressão quadrática, proporcionando melhor rendimento industrial quando os frutos foram colhidos no início de novembro, independentemente do porta-enxerto utilizado.

Termos para indexação: Citrus sinensis, qualidade do fruto, noroeste do Paraná.

\section{INDUSTRIAL QUALITY AND MATURATION OF FRUITS OF 'VALÊNCIA' SWEET ORANGE TREES ON SIX ROOTSTOCKS}

\begin{abstract}
In order to evaluate the influence of six rootstocks on the maturation and the physical characteristics and chemical composition of 'Valência' fruits, a research was conducted in a field established in 1994, in Nova Esperança city, state of Paraná, Brazil. A complete randomized block design was used, with four replications, three evaluated trees per plot and six treatments, constituted by the rootstocks: 'Rangpur' lime (Citrus limonia), 'Cleopatra' (C. reshni) and 'Sunki' (C. sunki) mandarins, 'Troyer' citrange (Poncirus trifoliata x C. sinensis), 'Orlando' tangelo (C. tangerina x C. paradisi) and 'Caipira' sweet orange (C. sinensis). Fruit quality was evaluated along seven harvesting seasons and the maturation curve was determined for the years of 1999 and 2000. All the evaluated rootstocks provided acceptable quality to 'Valência' orange fruits, with the 'Troyer' citrange inducing larger industrial juice yield, as compared to the Rangpur lime. In years with normal climatic pattern, the technological index response had a quadratic tendency of curve fitting, with larger industrial juice yield when fruits were harvested at the beginning of November, for any of the evaluated rootstocks.
\end{abstract}

Index terms: Citrus sinensis, Fruit quality, Northwest of Parana.

\section{INTRODUÇÃO}

Dentre as variedades de laranjas cultivadas no Brasil, a 'Valência' está entre as mais indicadas para a produção de suco, por apresentar bom rendimento e qualidade (Darros-Barbosa, 2006). A produção de suco com alta qualidade necessita, igualmente, de frutos com alta qualidade, sendo esta avaliada através das suas características físico-químicas que, por sua vez, variam durante o período de maturação e dependem, entre outros fatores, das condições meteorológicas durante a formação e maturação, dos frutos (Volpe et al., 2002). O clima como condicionante do cultivo dos citros interfere de forma decisiva na maturação, na taxa de crescimento e nas características físicas e químicas da fruta (Ortolani et al., 1991).

Os porta-enxertos também exercem importante influência sobre a qualidade do fruto, processo cuja interação com a variedade copa na absorção de

'(Trabalho 279-08). Recebido em: 11-11-2008. Aceito para publicação em: 29-07-2009.

${ }^{2} \mathrm{Eng}^{\mathrm{o}}$. Agr ${ }^{\circ}$. Doutorando na UEL, Pesquisador do Instituto Agronômico do Paraná. Paranavaí-PR (aulerpe@iapar.br)

${ }^{3}$ Enga $^{\mathrm{a}}$. Agr ${ }^{\mathrm{a}}$. Dra., Paranavaí-PR (acgfiori@yahoo.com.br)

${ }^{4}$ Farmacêutica. Dra., Pesquisadora do Instituto Agronômico do Paraná. Londrina-PR (mbscholz@iapar.br) 
água e nutrientes e com os reguladores vegetais estão entre os fatores mais importantes (Castle, 1995). Existe um grande número de características de qualidade dos frutos influenciadas pelos porta-enxertos, como tamanho e massa dos frutos, cor e espessura da casca, rendimento de suco, sólidos solúveis totais e acidez, cor do suco, conteúdo em óleo da casca, amargor, conteúdo em sais minerais, granulação, teor de ácidos graxos, conservação pós-colheita e época de maturação dos frutos (Stuchi et al., 1996; Pompeu Junior, 2005).

A citricultura brasileira tem sido periodicamente confrontada com doenças que podem assumir grandes proporções e que, em muitos casos, afetam determinadas combinações copa/porta-enxerto (Pompeu Junior, 2005), razão pela qual a diversificação de porta-enxertos, baseada em pesquisas regionais, é uma necessidade.

No Paraná, o limoeiro ‘Cravo’ ainda é o portaenxerto mais utilizado para todas as cultivares copas de citros, sendo ainda recentes os trabalhos voltados para este fim, utilizando como copa a laranja 'Valência' (Auler et al., 2008; Tazima et al., 2008). Novos estudos devem também incluir informações sobre a qualidade e a maturação dos frutos, aspectos de grande relevância para o processamento industrial.

O presente trabalho teve como objetivo avaliar as características físico-químicas de frutos de laranjeira 'Valência' enxertada em seis portaenxertos e caracterizar sua época de maturação na região noroeste do Paraná.

\section{MATERIAL E MÉTODOS}

A implantação do experimento ocorreu em janeiro de 1994, no sítio Laranjeira II, localizado a $5 \mathrm{~km}$ da cidade de Nova Esperança, situada no noroeste do Estado do Paraná, com clima Cfa, sem estação seca definida, de acordo com a classificação de Köeppen (IAPAR, 2000). O plantio, localizado no terço inferior da pendente, em Latossolo Vermelho distrófico, textura arenosa/média, foi realizado em camalhões, em espaçamento de $7 \mathrm{~m} \times 5 \mathrm{~m}$, sendo as plantas conduzidas sem irrigação. Utilizou-se o delineamento experimental de blocos casualizados, com quatro repetições, três plantas úteis por parcela e como tratamentos seis porta-enxertos: limoeiro 'Cravo' (Citrus limonia Osb.), tangerineiras 'Cleópatra' (Citrus reshni hort. ex Tan.) e 'Sunki' (Citrus sunki hort. ex Tan.), citrangeiro 'Troyer' [Poncirus trifoliata (L.) Raf. x Citrus sinensis (L.) Osb.], tangeleiro 'Orlando' (Citrus tangerina hort. ex Tan. x Citrus paradisi Macfad.) e laranjeira 'Caipira' [Citrus sinensis (L.) Osb.]. Como variedade copa foi utilizado o clone de laranja 'Valência 718', acesso I-94, proveniente da coleção de citros do Centro Avançado de Pesquisa Tecnológica do Agronegócio de Citros Sylvio Moreira, vinculado ao IAC, introduzido e disponibilizado aos citricultores paranaenses pelo Instituto Agronômico do Paraná.

A qualidade dos frutos foi avaliada no mês de outubro de 1998 a 2005, exceto em 2003. Foram coletadas amostras de nove frutos por parcela na altura mediana da copa. Esta amostragem também foi utilizada na determinação da massa média por fruto. Nos anos de 1999 e 2000, o mesmo número de frutos foi coletado mensalmente, de setembro a dezembro, para o acompanhamento da curva de maturação. Para essa avaliação, utilizou-se o delineamento de blocos ao acaso, em esquema de parcelas subdivididas no tempo, sendo os porta-enxertos (PE) as parcelas, e as épocas de coleta (meses) as subparcelas, com 4 repetições e 3 plantas úteis por parcela. Nestes anos, também foi realizada a avaliação da disponibilidade de água no solo, calculada segundo o método de Thornthwaite \& Mather (1955) para $100 \mathrm{~mm}$ de capacidade de armazenamento de água no solo. Os dados pluviométricos foram fornecidos pela Superintendência de Desenvolvimento de Recursos Hídricos e Saneamento Ambiental - SUDERHSA, Curitiba-PR, coletados em Estação Meteorológica (com coordenadas de $23^{\circ} 10^{\prime} \mathrm{S}$ e $52^{\circ} 10^{\prime} \mathrm{W}$ ) localizada a $5 \mathrm{~km}$ da área experimental; e os dados de temperatura fornecidos pelo IAPAR, coletados na Estação Meteorológica de Paranavaí, localizada a $30 \mathrm{~km}$ da área experimental e com altitude equivalente a esta $(480 \mathrm{~m})$.

Os frutos coletados foram submetidos às seguintes avaliações no Laboratório de Fisiologia Vegetal do IAPAR: massa dos frutos (g), rendimento do suco (RS, em \%) [(relação entre as massas do suco e dos frutos) x 100], com extração do suco obtida através de extratora marca Croydon ${ }^{\circledR}$ (550 Watts, $50 / 60$ ciclos); sólidos solúveis totais (SST), medidos em ${ }^{0}$ Brix por meio de leitura direta em refratômetro de bolso marca Kiltler, com os valores corrigidos para $20^{\circ} \mathrm{C}$; acidez titulável total (ATT) do suco, determinada por titulometria com solução de $\mathrm{NaOH}$ a $0,1 \mathrm{~N}$ e indicador fenolftaleína (AOAC, 1990), sendo os resultados expressos em porcentagem de ácido cítrico. O ratio foi calculado pela relação entre SST e ATT, e o índice tecnológico (IT), equivalente à quantidade de sólidos solúveis totais no suco $(\mathrm{kg})$, em uma caixa de colheita de frutos de $40,8 \mathrm{~kg}$, obtido pela seguinte fórmula: IT $=\left(\right.$ RS.SST.40,8) $/ 10^{4}(\mathrm{Di}$ Giorgi et al., 1990). Também foi calculado o rendimento industrial (RI), ou seja, o número de caixas por tonelada de suco concentrado, de acordo com a seguinte fórmula: $\mathrm{RI}=660 / \mathrm{IT}$, onde $660=660 \mathrm{~kg}$ 
de sólidos solúveis em $1.000 \mathrm{~kg}$ de suco concentrado e IT = índice tecnológico.

Os dados obtidos foram submetidos à análise de variância, sendo as médias dos fatores qualitativos (porta-enxertos) comparadas pelo teste de Tukey $(\mathrm{P} \leq 0,05)$, e o estudo do fator quantitativo (épocas de coleta), através de análise de regressão.

\section{RESULTADOS E DISCUSSÃO}

Com exceção da acidez (ATT) e do ratio, os porta-enxertos exerceram influência significativa sobre as demais características de qualidade dos frutos, considerando-se a média das sete safras avaliadas (Tabela 1). Os frutos de 'Valência' sobre citrangeiro 'Troyer' obtiveram os maiores valores de sólidos solúveis (SST), equivalentes à 'Caipira' e 'Sunki' e superiores ao 'Cravo', 'Cleópatra' e 'Orlando'. Esta variável (SST) foi a principal responsável pela diferenciação dos porta-enxertos em relação ao rendimento industrial e ao índice tecnológico, já que a influência do rendimento em suco foi menos pronunciada. Dessa forma, o maior valor de SST induzido por 'Troyer' conferiu a este porta-enxerto o maior índice tecnológico, superior ao 'Cravo' e 'Orlando' e, consequentemente, melhor rendimento industrial, necessitando de menor quantidade de caixas de laranja para produzir uma tonelada de suco a $66{ }^{0}$ Brix (Tabela 1$)$.

Estes resultados estão de acordo com Carlos et al. (1997), que relataram que o 'Troyer' induz ótima qualidade nas variedades copa nele enxertadas, e também com Zekri \& Al-Jallel (2004), que verificaram maior concentração de sólidos solúveis em frutos de laranjeira 'Valência' enxertada em citrangeiro ‘Carrizo' e redução na qualidade dos frutos em plantas enxertadas em porta-enxertos relativamente vigorosos, tais como o 'Cravo'. Da mesma forma, Georgiou (2004) verificou que o citrangeiro 'Troyer' induziu o valor mais alto de sólidos solúveis e acidez, seguido da laranjeira 'Azeda', entre 15 porta-enxertos avaliados, enquanto Stuchi et al. (2002), em três anos de avaliação, não constataram diferenças em laranjeira 'Valência' com 5 a 7 anos de idade, enxertada nos porta-enxertos tangeleiro 'Thornton' (Citrus reticulata x Citrus paradisi), citrangeiro 'Troyer', laranjeira 'Valência Americana', limoeiro 'Rugoso Nacional' (Citrus jambhiri), tangerineiras 'Cleópatra' e 'Sunki' e citrumeleiro 'Swingle' (Citrus paradise x Poncirus trifoliata) para os valores de acidez e ratio, sólidos solúveis e índice tecnológico, com exceção do rendimento em suco, onde 'Sunki' superou a 'Valência Americana'. Tazima et al. (2008), para a mesma variedade copa utilizada no presente estudo ('Valência 718'), porém enxertada em limoeiro 'Cravo', observaram um valor equivalente de índice tecnológico $(2,20)$, superior ao observado para 'Valência Late 1138'.

Em rendimento de suco, a 'Cleópatra' superou a 'Caipira', não diferindo dos demais porta-enxertos (Tabela 1). Por sua vez, Sarooshi \& Hutton (1992) verificaram que sete variedades de laranja, entre as quais 'Seedless Valencia', tiveram os maiores valores de rendimento de suco, em sete anos de avaliação, quando enxertadas em citrangeiro 'Troyer'.

A maior massa média dos frutos ocorreu nas plantas enxertadas em 'Cravo', 'Caipira', 'Orlando' e 'Sunki', enquanto 'Troyer' e 'Cleópatra' proporcionaram frutos de menor tamanho e inferiores ao 'Cravo' (Tabela 1). Tais resultados estão em acordo com os encontrados por Stuchi et al. (2002), que verificaram não haver diferenças significativas entre a massa dos frutos de plantas enxertadas em citrangeiro 'Troyer', e nas tangerineiras 'Cleópatra'e 'Sunki', e também com Carlos et al. (1997), que relataram que a 'Cleópatra' induziu pequeno tamanho de fruto. Observa-se também que os frutos com maior massa não proporcionaram maior conteúdo de suco (Tabela 1), ao contrário do que foi constatado por Holguín et al. (1992).

Verificou-se que o porta-enxerto 'Troyer' induziu frutos com menor massa e produziu mais sólidos solúveis por caixa ou maior índice tecnológico (Tabela 1), conforme também relatado por Di Giorgi et al. (1993), que constataram que assim como os sólidos solúveis, o rendimento industrial está inversamente associado ao tamanho dos frutos, a partir da observação de correlação negativa entre Brix e massa do fruto para as cultivares Pera e Natal.

O comportamento do índice tecnológico para cada uma das safras avaliadas (1998 a 2005), não foi influenciado pelos porta-enxertos antes da safra de 2000, ou seja, antes do $6^{\circ}$ ano após o plantio (Tabela 2). Variações foram observadas nos anos de 2000, 2002 e 2004, destacando-se a superioridade do 'Troyer' em relação ao 'Cravo' e 'Orlando' que tiveram os piores valores de IT. Observou-se também, de maneira geral, o crescimento deste índice a partir da safra de 2001 em relação às anteriores, independentemente do porta-enxerto utilizado (Tabela 2). Resultados obtidos por Roka et al. (2000) demonstraram que o índice tecnológico aumentou durante os primeiros 10 anos de idade das plantas para todas as cultivares estudadas (Hamlin, Valência e Rhode Valência), enxertadas em 'Carrizo' e 'Swingle', tendo alcançado um platô em plantas com 10 a 13 anos de idade.

De acordo com Albrigo (1992), nas con- 
dições da Flórida, 60 a $70 \%$ da variabilidade de ano para ano, em relação ao índice tecnológico e sólidos solúveis, podem ser devidas às oscilações de temperatura e chuva nas épocas-chave do ano, como o período da diferenciação e indução floral, responsável por $40 \%$ da variação entre anos da qualidade do fruto.

\section{Curva de maturação dos frutos}

Não houve interação significativa entre os porta-enxertos e a época de coleta dos frutos, indicando que os porta-enxertos não tiveram um comportamento diferenciado sobre a maturação dos frutos para as épocas de coleta avaliadas, de setembro a dezembro de 1999 e 2000 (dados não apresentados). Embora não observada neste estudo, a influência de porta-enxertos sobre a maturação de frutos é conhecida (Stuchi et al., 1996; Stenzel et al., 2006). Estes últimos autores, tendo observado diferenças sobre a época de maturação dos frutos de laranjeira 'Folha-Murcha' (Citrus sinensis), onde os limões 'Cravo' e 'Volkameriano' (Citrus volkameriana) anteciparam a maturação em relação às tangerinas 'Cleópatra' e 'Sunki'.

Porém, de forma isolada, tanto o portaenxerto (dados não apresentados) como a época de coleta (Figuras 1 e 2) tiveram efeito significativo sobre as variáveis de qualidade do fruto, ainda que de forma diferenciada para os anos 1999 e 2000. $\mathrm{Na}$ média das coletas realizadas de setembro a dezembro, no ano de 2000, os porta-enxertos exerceram efeito significativo sobre a massa média dos frutos, sólidos solúveis, ratio, rendimento industrial e índice tecnológico (dados não apresentados), de forma equivalente ao observado na média do período de 1998 a 2005 (Tabela 1). No ano de 1999, não houve diferenças entre os porta-enxertos para as variáveis avaliadas, com exceção da massa média dos frutos, onde se verificou que 'Troyer' induziu o menor valor, diferindo apenas do 'Cravo' (dados não apresentados), conforme também observado com 'Troyer' e 'Cleópatra' no período de 1998 a 2005 (Tabela 1).

Para o efeito da época de coleta dos frutos sobre a curva de maturação, também ocorreu uma diferenciação entre estes anos em relação ao comportamento das variáveis (Figuras 1 e 2). Em 1999, o comportamento das médias para rendimento do suco e índice tecnológico ao longo do período de coleta não permitiu o ajuste da curva de maturação através da análise de regressão, enquanto os sólidos solúveis e a acidez apresentaram ajuste linear, com valores crescentes para sólidos solúveis e decrescentes para acidez até a última coleta realizada em dezembro (Figura 1).
Com exceção da acidez, no ano de 2000, foi possível ajustar curvas quadráticas para estas variáveis (Figura 1). O rendimento em suco atingiu o valor máximo de $49,78 \%$ em 31 de outubro $(x=2,34)$, o índice tecnológico, valor máximo de 2,10 em 3 de novembro $(\mathrm{x}=2,43)$ e os sólidos solúveis, 10,34 ${ }^{0}$ Brix $(x=2,78)$ em 15 de novembro, com reduções nos períodos posteriores (Figura 1). O valor máximo obtido com o índice tecnológico, no início de novembro, independentemente do porta-enxerto utilizado, indica, para a colheita realizada neste período, melhor aproveitamento da matéria-prima em termos de rendimento industrial, diferindo dos demais períodos avaliados.

Volpe et al. (2002) também obtiveram um ajuste quadrático para o índice tecnológico, em avaliação da maturação de frutos de laranja 'Valência' e 'Natal', com coletas também realizadas até dezembro. Esses autores ressaltam que o índice tecnológico não constitui o resultado de uma medida e, sim, de um cálculo, cujos parâmetros são o teor de sólidos solúveis e o rendimento em suco, sendo, portanto, influenciado por todos os fatores que afetam esses parâmetros. Em relação ao SST, Pérez \& Sánchez (2004) consideram que o decréscimo observado nos meses posteriores ao ponto de máximo valor pode ser consequência da diluição do suco causada por fenômenos atmosféricos (precipitação e temperatura) associados ao regime hídrico da planta, como foi observado neste estudo (Figuras 3 e 4).

O modelo de regressão linear permitiu o melhor ajuste para a variável acidez, que apresentou valores decrescentes durante o período avaliado, com comportamento semelhante nos anos de 1999 e 2000 (Figura 1). O decréscimo na concentração de ácido até a maturação é, entre outros fatores, o resultado do aumento do tamanho do fruto e do acúmulo de água que dilui a concentração do ácido (Kimball, 1984).

O ratio também apresentou evolução linear com valores crescentes durante o período avaliado, variando de 9 a 14,2 para 1999 e de 7,9 a 13,2 para o ano de 2000 (Figura 2). Considerando que o ratio ideal para indústria está situado entre 11 e 14 (Stuchi et al., 1996), esses valores foram atingidos, respectivamente, em 23 de outubro e 18 de dezembro para o ano de 1999, e em 06 de novembro e 21 de dezembro no ano de 2000. Estes resultados indicam que, sob condições de menor precipitação e deficiência hídrica (Figuras 3 e 4), a maturação dos frutos tende a ser antecipada. Segundo Volpe et al. (2002), o ratio ou índice de maturidade é o método de avaliação utilizado para determinar a maturidade e a época de colheita dos frutos de laranja. Estes autores também obtiveram melhor ajuste para esta variável com a equação de 
regressão linear simples, para frutos de 'Valência' e 'Natal', avaliados até dezembro. Blumer et al. (2003) observaram evolução semelhante do ratio, de 8,2 a 14,0, de agosto a dezembro, em avaliação de sete clones de laranja 'Valência'.

Considerando-se o regime climático da região onde o estudo foi desenvolvido, o ano de 2000 foi considerado normal, e o de 1999 atípico, com períodos de deficiência hídrica acima da média e temperaturas médias mais altas, principalmente no segundo semestre, que coincidiram com o período de coleta e avaliação da maturação dos frutos, o que deve explicar as diferenças observadas entre estes anos (Figuras 3 e 4).

Dos muitos fatores que podem influenciar no crescimento do fruto, a disponibilidade de água e a temperatura exercem maior influência na morfologia e na qualidade interna da fruta (García \& Fernández, 1981). A umidade excessiva proporcionada por longos períodos de chuva aumenta o tamanho dos frutos, mas dilui os sólidos solúveis, ácidos e outros componentes. Por outro lado, períodos de aridez também afetam de forma adversa o desenvolvimento do fruto e também a fotossíntese e, consequentemente, o acúmulo de açúcar (Albrigo, 1992). Núñez \& Iglesias (1991), em dez anos de avaliação, verificaram haver maior associação do rendimento de suco com a temperatura do que com a precipitação.

A qualidade do fruto é uma característica inerente da cultivar copa que pode ser modificada, mas não radicalmente mudada, sem manipulação genética (Castle, 1995). Algumas cultivares de laranja, como 'Valência', são naturalmente de alta qualidade, e a escolha do porta-enxerto pode ser menos significativa do que para uma laranja de qualidade inferior. A magnitude do efeito do porta-enxerto nos fatores de qualidade do fruto pode variar de 5\% a 30\% (Castle, 1995), enquanto sobre a produção de frutos pode chegar a 70\%, conforme relatado por Auler et al. (2008), neste mesmo experimento, devendo, portanto, ser considerado, juntamente com os dados de qualidade do fruto, na seleção de porta-enxertos.
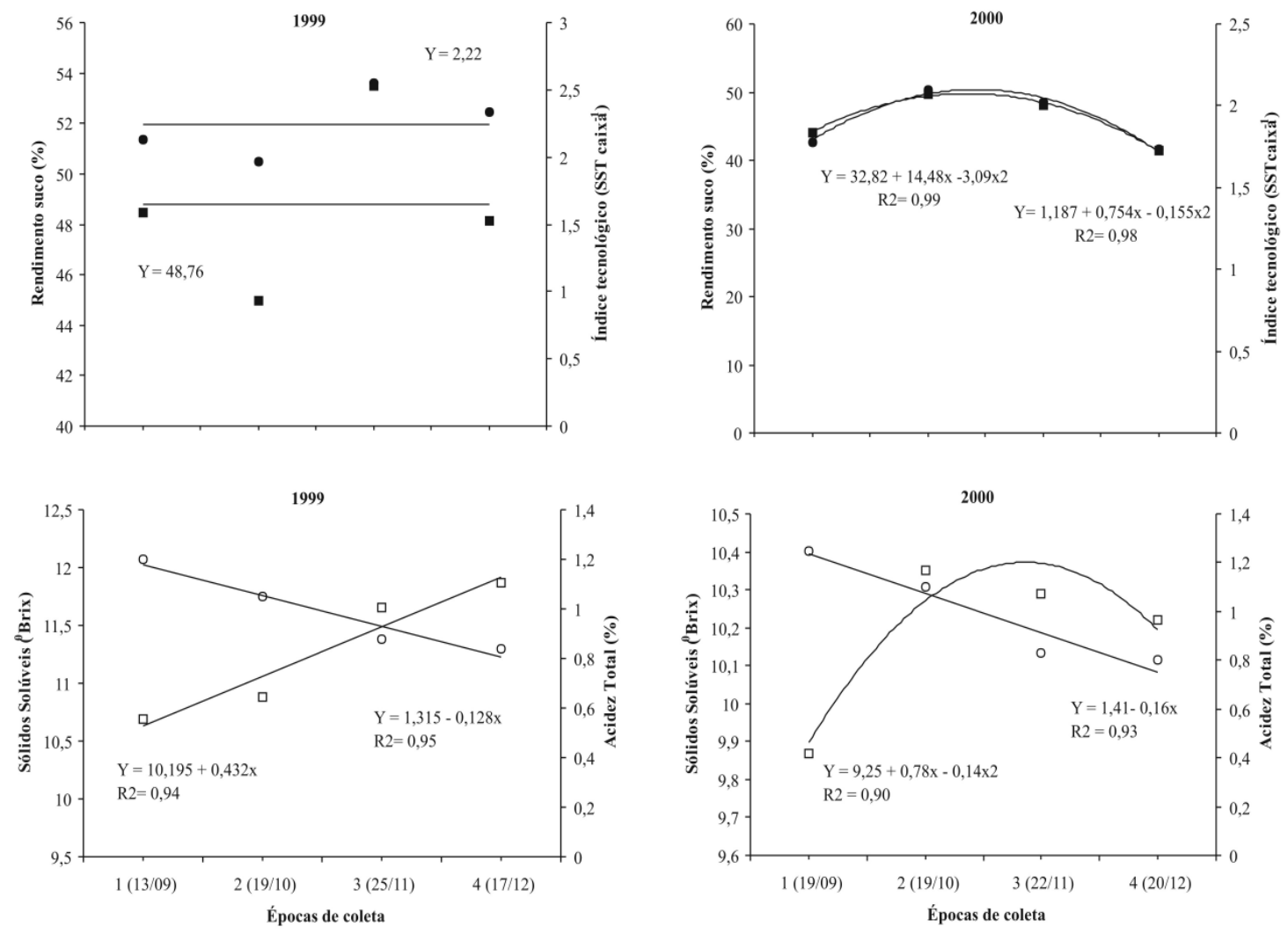

FIGURA 1- Rendimento em suco (ロ), índice tecnológico (•), teores de sólidos solúveis totais (SST) ( $\square$ ) e acidez total titulável (ATT) (०) de frutos de laranjeira 'Valência', em função das épocas de coleta dos frutos, nos anos de 1999 e 2000. 


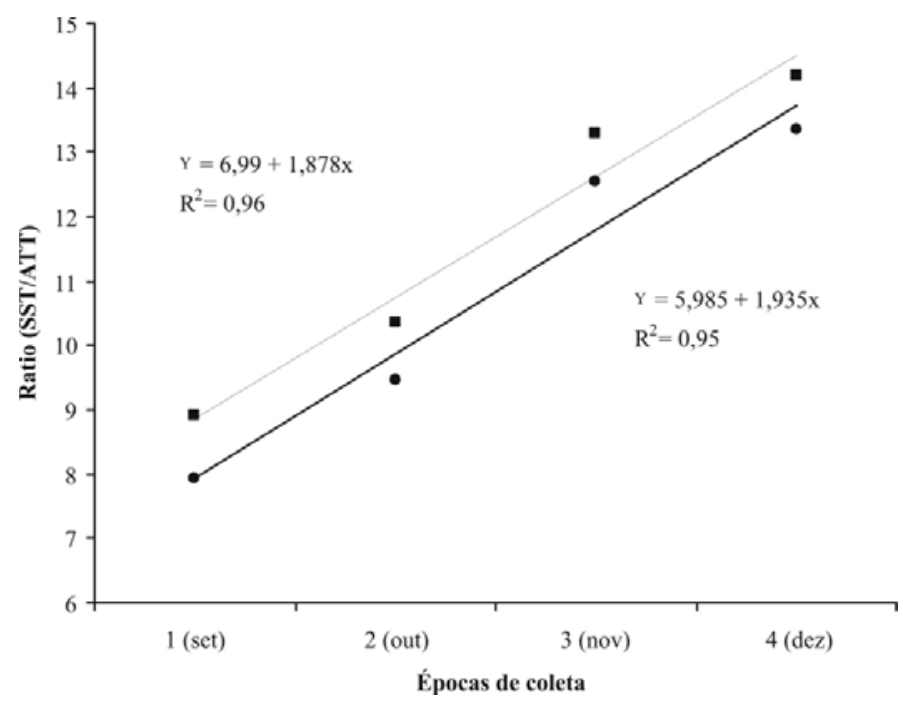

FIGURA 2- Ratio dos frutos de laranjeira 'Valência' em função da época de coleta dos frutos, nos anos de (匹) 1999 e (•) 2000.
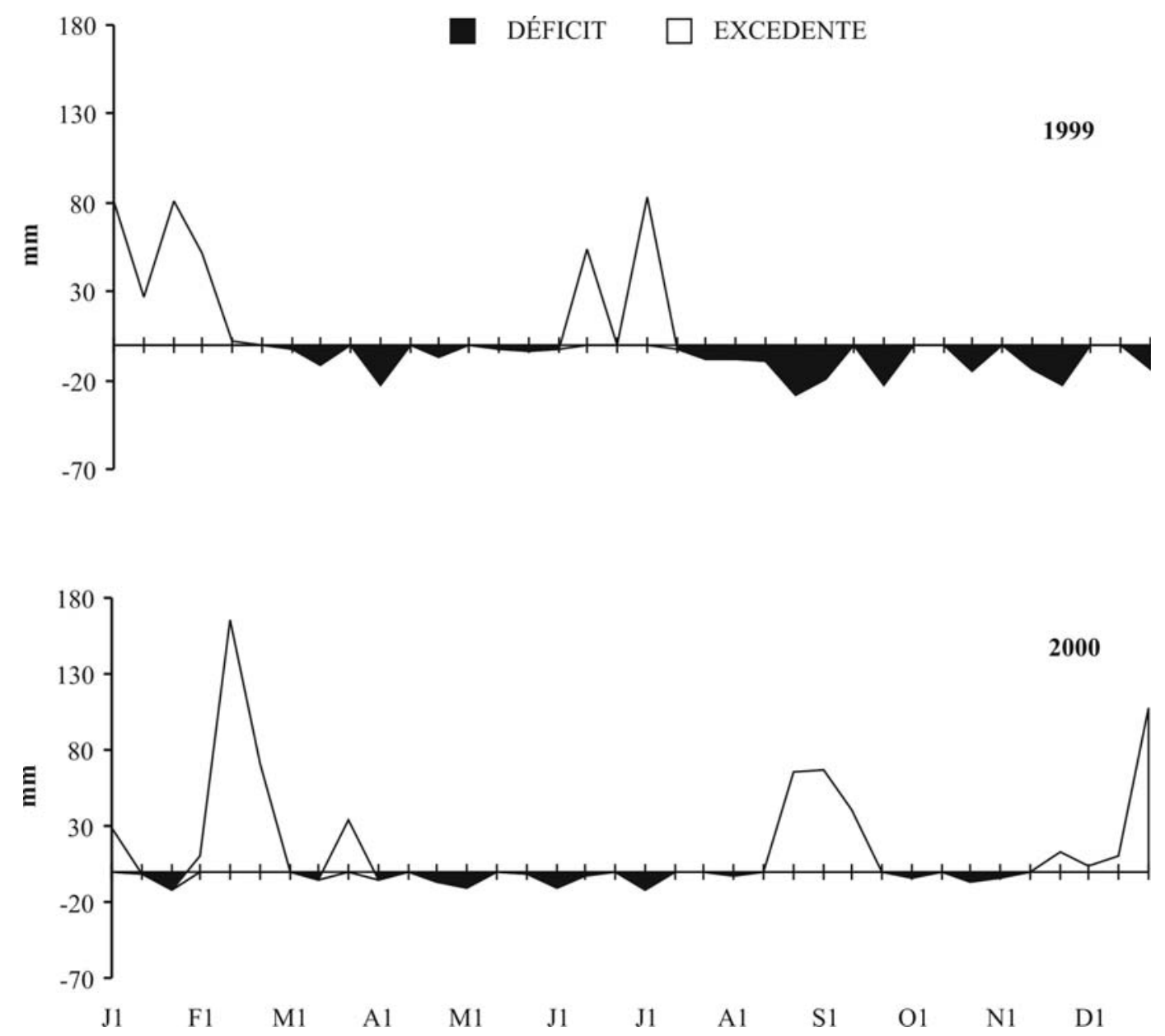

FIGURA 3 - Balanço hídrico estimado pelo modelo Thornthwaite e Mather (1955) para o período de janeiro a dezembro de 1999 e 2000 (decêndios), Nova Esperança-PR. 
ppt $\cdots \cdot$ m.

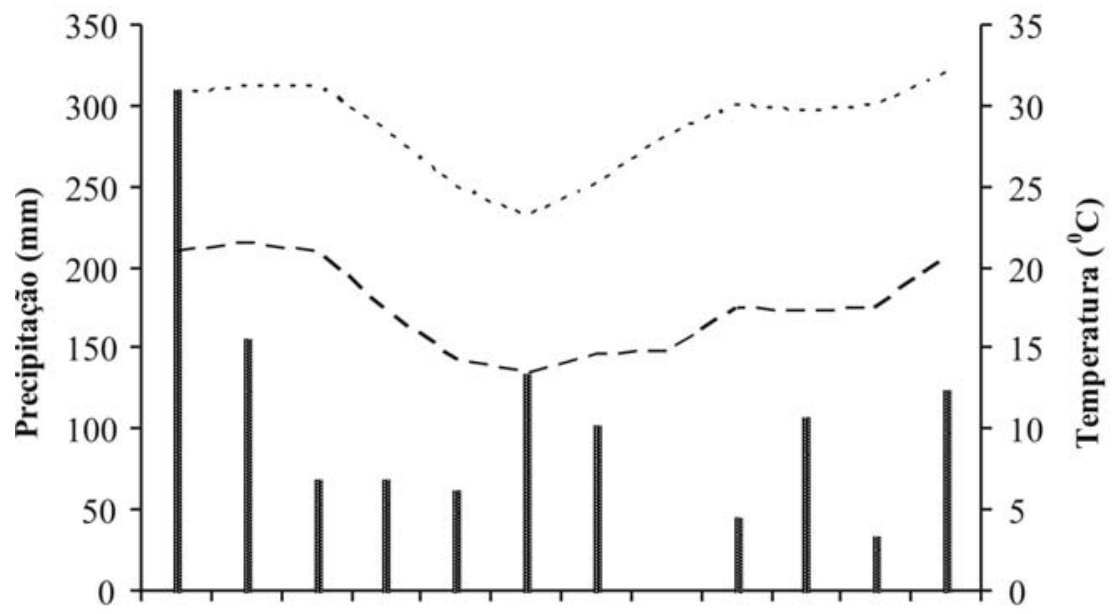

jan fev mar abr mai jun jul ago set out nov dez

Ano de 1999

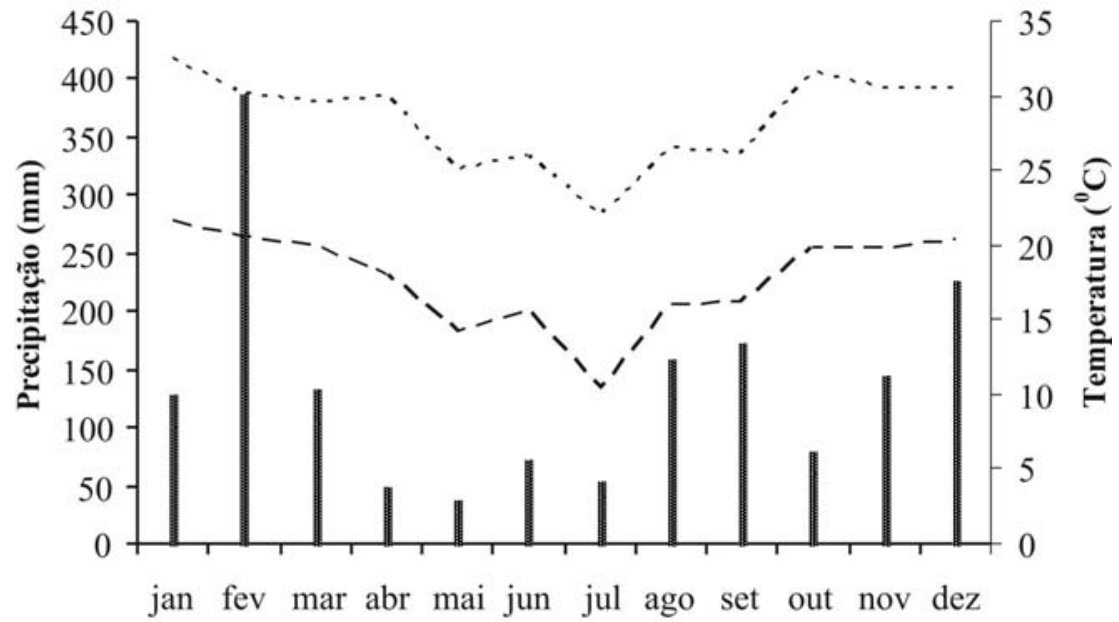

Ano de 2000

FIGURA 4-Médias mensais nos anos de 1999 e 2000 da precipitação pluvial (ppt) e temperatura do ar, máxima (tmáx.) e mínima (tmín.), Nova Esperança-PR. 
TABELA 1 - Características médias de qualidade e rendimento industrial de frutos de laranjeira 'Valência' sobre seis porta-enxertos, Nova Esperança, PR.

\begin{tabular}{|c|c|c|c|c|c|c|c|c|c|c|c|c|c|}
\hline \multirow{2}{*}{$\begin{array}{l}\text { Porta- } \\
\text { enxertos }\end{array}$} & \multicolumn{2}{|c|}{$\begin{array}{c}\text { Massa } \\
\text { média } \\
(\mathrm{g})\end{array}$} & \multicolumn{2}{|c|}{$\begin{array}{c}\text { Rendimento } \\
\text { suco } \\
(\%)\end{array}$} & \multicolumn{2}{|c|}{$\begin{array}{l}\text { Sólidos } \\
\text { sol.totais } \\
\text { (SST) } \\
\left({ }^{\circ} \text { Brix) }\right.\end{array}$} & \multicolumn{2}{|c|}{$\begin{array}{c}\text { Acidez } \\
\text { tit.total } \\
\text { (ATT) } \\
(\%)\end{array}$} & \multicolumn{2}{|c|}{$\begin{array}{l}\text { Ratio } \\
\text { (SST/ } \\
\text { ATT) }\end{array}$} & $\begin{array}{l}\text { Rendimento } \\
\text { industrial } \\
\left(\mathrm{Cx} . \mathrm{t}^{-1} \text { suco }\right)\end{array}$ & \multicolumn{2}{|c|}{$\begin{array}{c}\text { Índice } \\
\text { tecnológico } \\
(\mathrm{SST} / \mathrm{Cx})\end{array}$} \\
\hline & $193,0^{1}$ & $\mathrm{a}^{2}$ & 50,3 & $a b$ & 10,3 & $\mathrm{c}$ & 0,92 & $\mathrm{a}$ & 11,6 & $\mathrm{a}$ & $315,9 \quad a$ & 2,16 & $\mathrm{~b}$ \\
\hline Cleópatra & 176,0 & $\mathrm{~b}$ & 51,3 & $\mathrm{a}$ & 10,7 & $\mathrm{bc}$ & 0,99 & $\mathrm{a}$ & 11,1 & $\mathrm{a}$ & $297,6 \quad a b$ & 2,29 & $a b$ \\
\hline Sunki & 181,8 & $a b$ & 50,0 & $a b$ & 10,9 & $a b$ & 1,03 & $\mathrm{a}$ & 10,9 & $\mathrm{a}$ & $302,0 \quad a b$ & 2,27 & $a b$ \\
\hline Troyer & 175,1 & $\mathrm{~b}$ & 50,6 & $a b$ & 11,4 & $\mathrm{a}$ & 0,98 & $\mathrm{a}$ & 12,0 & $\mathrm{a}$ & $285,9 \quad b$ & 2,40 & $\mathrm{a}$ \\
\hline Orlando & 188,6 & $a b$ & 49,8 & $a b$ & 10,6 & $\mathrm{bc}$ & 0,99 & $\mathrm{a}$ & 11,1 & $\mathrm{a}$ & $311,3 \quad a b$ & 2,20 & b \\
\hline Caipira & 189,2 & $a b$ & 48,8 & $\mathrm{~b}$ & 11,1 & $a b$ & 1,02 & $\mathrm{a}$ & 11,1 & $\mathrm{a}$ & $302,6 \quad a b$ & 2,24 & $\mathrm{ab}$ \\
\hline CV (\%) & \multicolumn{2}{|c|}{3,9} & \multicolumn{2}{|c|}{1,9} & \multicolumn{2}{|c|}{2,4} & \multicolumn{2}{|l|}{5,4} & \multicolumn{2}{|c|}{6,6} & 4,0 & \multicolumn{2}{|c|}{3,8} \\
\hline
\end{tabular}

TABELA 2 - Índice tecnológico de frutos de laranjeira 'Valência' sobre seis porta-enxertos, das safras de 1998 a 2005, exceto 2003, Nova Esperança, PR.

\begin{tabular}{|c|c|c|c|c|c|c|c|c|c|c|c|c|c|}
\hline \multirow{2}{*}{$\begin{array}{l}\text { Safras / } \\
\text { Anos }^{1} \\
1998 / 4^{\circ}\end{array}$} & \multicolumn{2}{|c|}{ Cravo } & \multicolumn{2}{|c|}{ Cleópatra } & \multicolumn{2}{|c|}{ Sunki } & \multicolumn{2}{|c|}{ Troyer } & \multicolumn{2}{|c|}{ Orlando } & \multicolumn{2}{|c|}{ Caipira } & \multirow{2}{*}{$\begin{array}{l}\text { CV } \\
(\%) \\
8,8\end{array}$} \\
\hline & 1,82 & $a^{2}$ & 1,87 & $\mathrm{a}$ & 1,86 & $\mathrm{a}$ & 2,05 & $\mathrm{a}$ & 1,83 & $\mathrm{a}$ & 1,91 & $\mathrm{a}$ & \\
\hline $1999 / 5^{\circ}$ & 1,94 & $\mathrm{a}$ & 2,01 & $\mathrm{a}$ & 1,91 & $\mathrm{a}$ & 2,03 & $\mathrm{a}$ & 1,98 & $\mathrm{a}$ & 1,97 & $\mathrm{a}$ & 8,7 \\
\hline $2000 / 6^{\circ}$ & 2,00 & $\mathrm{c}$ & 2,23 & $a b$ & 2,06 & $\mathrm{bc}$ & 2,29 & $\mathrm{a}$ & 1,95 & $\mathrm{c}$ & 2,09 & $a b c$ & 4,8 \\
\hline $2001 / 7^{0}$ & 2,44 & $\mathrm{a}$ & 2,45 & $\mathrm{a}$ & 2,47 & $\mathrm{a}$ & 2,57 & $\mathrm{a}$ & 2,42 & $\mathrm{a}$ & 2,33 & $\mathrm{a}$ & 6,4 \\
\hline $2002 / 8^{\circ}$ & 2,44 & $\mathrm{~b}$ & 2,57 & $a b$ & 2,61 & $a b$ & 2,73 & $\mathrm{a}$ & 2,44 & $\mathrm{~b}$ & 2,48 & $\mathrm{~b}$ & 3,8 \\
\hline $2004 / 10^{\circ}$ & 2,19 & $\mathrm{~b}$ & 2,44 & $a b$ & 2,46 & $\mathrm{a}$ & 2,52 & $\mathrm{a}$ & 2,39 & $a b$ & 2,39 & $a b$ & 4,9 \\
\hline $2005 / 11^{\circ}$ & 2,28 & $\mathrm{a}$ & 2,43 & $\mathrm{a}$ & 2,49 & $\mathrm{a}$ & 2,62 & $\mathrm{a}$ & 2,36 & $\mathrm{a}$ & 2,53 & $\mathrm{a}$ & 7,7 \\
\hline
\end{tabular}

\section{CONCLUSÃO}

1-Todos os porta-enxertos utilizados (limoeiro 'Cravo', tangerineiras 'Cleópatra' e 'Sunki', citrangeiro 'Troyer', tangeleiro 'Orlando' e laranjeira 'Caipira') proporcionaram qualidade aceitável aos frutos da laranjeira 'Valência' (clone 718), com destaque para o 'Troyer', que superou o 'Cravo' em rendimento industrial.

2-Em ano considerado com padrão climático normal, a evolução do índice tecnológico ajustou-se a uma equação de regressão quadrática, proporcionando melhor rendimento industrial quando os frutos são colhidos no início de novembro, independentemente do porta-enxerto utilizado.

\section{AGRADECIMENTOS}

Aos citricultores Gilberto e Antônio Pratinha, pela cessão da área experimental e apoio na condução do experimento. Ao Eng ${ }^{\circ}$. Agr ${ }^{\circ}$. Marcos Loli, da Citri Agroindustrial SA, pelo apoio nas análises dos frutos. Ao ex-pesquisador do IAPAR, Professor Ângelo Pedro Jacomino, pela instalação e condução inicial deste experimento.

\section{REFERÊNCIAS}

ALBRIGO, L.G. Influências ambientais no desenvolvimento de frutos cítricos. In: SEMINÁRIO INTERNACIONAL DE CITROS: FISIOLOGIA, 2., Bebedouro, 1992. Anais... Campinas: Fundação Cargill, 1992. p. 100-106. 
AOAC-ASSOCIATION OF OFFICIALANALYTICAL CHEMISTS. Official methods of analysis. $15^{\text {th }}$ ed. Arlington, 1990. 1.298p.

AULER, P.A.M.; FIORI-TUTIDA, A.C.G.; TAZIMA, Z.H. Comportamento da laranjeira 'Valência' sobre seis porta-enxertos no noroeste do Paraná. Revista Brasileira de Fruticultura, Jaboticabal, v. 30, n. 1, p. 229-234, 2008.

BLUMER, S.; POMPEU JUNIOR, J.; GARCIA, V.X.P. Características de qualidade dos frutos de laranjas de maturação tardia. Laranja, Cordeirópolis, v. 24, n. 2, p. 423-431, 2003.

CARLOS, E. F.; STUCHI, E.S.; DONADIO, L.C. Porta-enxertos para a citricultura paulista. Jaboticabal: Funep, 1997. 47p. (Boletim Citrícola, 1).

CASTLE, W.S. Rootstock as a fruit quality factor in citrus and deciduous tree crops. New Zealand Journal of Crop and Horticultural Science, New Zealand, v. 23, p. 383-394, 1995.

DARROS-BARBOSA. Colheita, beneficiamento, embalagem, conservação e comercialização. In: KOLLER, O.C. Citricultura: 1. Laranja: tecnologia de produção, pós-colheita, industrialização e comercialização. Porto Alegre: Cinco Continentes, 2006. cap. 10, p. 310-331.

DI GIORGI, F.; IDE, B.Y.; DIB, K.; MARCHI, R.J. ; TRIBONI, H.R. ; WAGNER, R.L. Contribuição ao estudo do comportamento de algumas variedades de citros e suas implicações agroindustriais. Laranja, Cordeirópolis, v. 11, n. 2, p. 567-612, 1990.

DI GIORGI, F.; IDE, B.Y.; DIB, K.; MARCHI, R.J. ; TRIBONI, H.R. ; MARCHI, R.J. WAGNER, R.L. Qualidade da laranja para industrialização. Laranja, Cordeirópolis, v. 14, n. 1, p. 97-118, 1993.

GARCÍA, C.D.S.; FERNÁNDEZ, M.A. Climatic effects on 'Valencia' oranges in eastern Cuba. Proceedings of the International Society of Citriculture, Washington, v.1, p. 331-334, 1981.

GEORGIOU, A. Evaluation of rootstocks for 'Valencia' orange. Agricoltura Mediterranea, Pisa, v. 134, p. 193-200, 2004.

HOLGUÍN, E.C.L.; ANGEL, S.G.A.; BAENA, G.D.; ESCOBAR, T.W. Effecto de cinco portainjertos sobre la floración, fructificación y madura- ción de la naranja 'Frost Valencia' Citrus sinensis (L). Osb. En condiciones del CNI-Palmira, Valle del Cauca. Acta Agronomica, Palmira, v. 42, n. 1/4, p. 81-96, 1992.

IAPAR - Instituto Agronômico do Paraná. Cartas climáticas do Paraná: versão 1.0. Londrina: IAPAR, 2000. CD-ROM.

KIMBALL, D.A. Factors affecting the rate of maturation of citrus fruits. Proceeding of Florida State Horticultural Society, Gainesville, n. 97, p. 40-44, 1984.

NÚÑEZ, M.; IGLESIAS, L. Relaciones entre los principales indicadores del crecimiento y la calidad interna de los frutos de naranja Valencia y algunas variables meteorológicas. Cultivos Tropicales, La Habana, v. 12, n. 3, p. 57-61, 1991.

ORTOLANI, A.A.; PEDRO JR., M.J.; ALFONSI, R.R. Agroclimatologia e o cultivo dos citros. In: RODRIGUEZ, O.; VIEGAS, F.C.P.; POMPEU JR., J.; AMARO, A.A. Citricultura brasileira. 2. ed. Campinas: Fundação Cargill, 1991, v. 1, p. 153-193.

PÉREZ, Y.; SÁNCHEZ, C.M. Effecto de la época de recolección de la naranja (Citrus sinensis L.) variedad 'Valencia Late' sobre el procesamiento industrial de cítricos en las tres grandes regiones edafoclimáticas de Cuba. Cultivos Tropicales, La Habana, v. 25, n. 4, p. 27-31, 2004.

POMPEU JUNIOR, J. Porta-enxertos. In: MATTOS JR., D.; DE NEGRI, J.D.; PIO, R.M.; POMPEU JUNIOR, J. Citros. Campinas: Instituto Agronômico e Fundag, 2005. p. 63-94.

ROKA, F.M.; ROUSE, R.E.; MURARO, R.P. Comparison of yields by tree age and rootstock in southwest Florida orange groves. Proceeding of Florida State Horticultural Society, Gainesville, v. 113, p. 115-119, 2000.

SAROOSHI, R.A.; HUTTON, R.J. Midseason oranges for juice production. Australian Journal of Experimental Agriculture, Collingwood, v. 32, p. 1.141-1.151, 1992.

STENZEL, N.M.C.; NEVES, C.S.V.J.; MARUR, C.J.; SCHOLZ, M.B.S.; GOMES, J.C. Maturation curves and degree-days accumulation for fruits of 'Folha Murcha' orange trees. Scientia Agrícola, Piracicaba, v. 63, n. 3, p. 219-225, 2006. 
STUCHI, E.S.; DONADIO, L.C.; SEMPIONATO, O.R. Qualidade industrial e produção de frutos de laranjeira 'Valência' enxertada sobre sete portaenxertos. Laranja, Cordeirópolis, v. 23, n. 2, p. 453-471, 2002.

STUCHI, E.S.; SEMPIONATO, O.R.; SILVA, J.A.A. Influência dos porta-enxertos na qualidade dos frutos cítricos. Laranja, Cordeirópolis, v. 17, n. 1, p. 143-158, 1996.

TAZIMA, Z.H.; AULER, P.A.M.; NEVES, C.S.V.J.; YADA, I.F.U.; LEITE JUNIOR, R.P. Comportamento de clones de laranja 'Valência' na região norte do Paraná. Revista Brasileira de Fruticultura, Jaboticabal, v. 30, n. 4, p. 970-974, 2008.
THORNTHWAITE, C.W.; MATHER, J.R. The water balance. New Jersey: Laboratory of Climatology, 1955. 104p. (Publications in climatology, 8).

VOLPE, C.A.; SCHÖFFEF, E.R.; BARBOSA, J.C. Influência da soma térmica e da chuva durante o desenvolvimento de laranjas 'Valência' e 'Natal' na relação entre sólidos solúveis e acidez e no índice tecnológico do suco. Revista Brasileira de Fruticultura, Jaboticabal, v. 24, n. 2, p. 436-441, 2002.

ZEKRI, M.; AL-JALEEL, A. Evaluation of rootstocks for Valencia and Navel orange trees in Saudi Arábia. Fruits, Paris, v.59, n.2, p.91-100, 2004. 